\title{
Lapurdum
}

LAPURDUM Euskal ikerketen aldizkaria | Revue d'études basques |

Revista de estudios vascos | Basque studies review

$11 \mid 2006$

Numéro XI

\section{El cuento contemporáneo en Euskara}

\section{Mari Jose Olaziregi}

\section{CpenEdition}

\section{Journals}

\section{Edición electrónica}

URL: http://journals.openedition.org/lapurdum/363

DOI: 10.4000/lapurdum.363

ISSN: 1965-0655

Editor

IKER

Edición impresa

Fecha de publicación: 1 noviembre 2006

Paginación: 271-280

ISBN: 978-2-86781-474-7

ISSN: $1273-3830$

\section{Referencia electrónica}

Mari Jose Olaziregi, «El cuento contemporáneo en Euskara », Lapurdum [En línea], 11 | 2006,

Publicado el 01 abril 2008, consultado el 19 abril 2019. URL : http://journals.openedition.org/ lapurdum/363 ; DOI : 10.4000/lapurdum.363 


\title{
El cuento contemporáneo en Euskara $^{1}$
}

\author{
Mari Jose OLAZIREGI \\ Universidad del País Vasco \\ mj.olaziregi@ehu.es
}

\section{El cuento moderno en lengua vasca. Evolución y presentación de tendencias actuales.}

El cuento, en el sentido moderno del término, es un género bastante reciente en la literatura en lengua vasca. De hecho, no es hasta la década de los años cincuenta y sesenta del pasado siglo cuando aparecen de la mano de autores como Gabriel Aresti (Ipuinak, [Cuentos] 1979) o Jon Mirande (Gauez parke batean -Ipuin izugarriak-, [De noche en el parque. Cuentos terribles] 1984), cuentos que siguen la tradición moderna de Poe, Gogol o Maupassant, entre otros. También podríamos mencionar el libro de cuentos Iltzalleak [Los asesinos] (1961) como un buen antecedente del que sería el primer libro de cuentos modernos publicado en euskara: Hunik arrats artean ('Hasta la noche', 1970) de Anjel Lertxundi. Eran evidentes en él los ecos del realismo mágico (García Márquez, Rulfo...), o de la literatura del absurdo (Kafka, Artaud...). Otros libros de cuentos que se publicaron en la misma década continuaron la senda de los relatos tradicionales o acertaron a incorporar el experimentalismo tan en boga en las novelas vascas de la época (como la narración Zergatik bai [Porque sí] (1976) de Koldo Izagirre, o algún cuento de J.A Arrieta o I. Sarasola). En cualquier caso, si hay una década que marcó un punto de inflexión en la evolución del cuento moderno vasco, esa fue la de los años 80. Al igual que sucediera en la literatura española, el incremento de revistas literarias y premios favoreció un renacimiento del cuento. Pero en el caso vasco habría que añadir otros factores sociohistóricos que pudieron también propiciar el auge de las publicaciones de relatos. Nos referimos a la nueva coyuntura política, gracias a la cual el sistema literario vasco pudo tener, por primera vez, las mejores condiciones objetivas para su pleno desarrollo. Hablamos de una época en la que la Ley de Normalización del Uso del Euskara (1982) impulsó la cooficialidad del euskara y propició el aumento de lectores euskaldunes que, sea desde la educación secundaria, sea desde las academias de euskaldunización, demandaron nuevas lecturas literarias. A las variantes sociopolíticas mencionadas se unió la irrupción en

1 - Este artículo incluye básicamente las reflexiones que presentamos en nuestro prólogo a la antología: Pintxos. Nuevos cuentos vascos (Lengua de Trapo, 2005, Madrid). 
el panorama literario Vasco de la banda Pott ('Fracaso'; 1978-1980), grupo literario integrado por Bernardo Atxaga, Joseba Sarrionandia, Joxemari Iturralde, Ruper Ordarika, Manu Erzilla y Jon Juaristi. La renovación poética que lideraba Pott tuvo su realización más plena en géneros breves como el cuento y la poesía. No deja de ser significativo el hecho de que el primer Premio Nacional de Narrativa otorgado a una obra escrita en lengua vasca lo fuera a Obabakoak (1988), libro en el que Atxaga incluyó muchos de los cuentos anteriormente publicados en la revista Pott. Además de Obabakoak, el libro de relatos Narrazioak ('Narraciones', 1983), de Joseba Sarrionandia, es un claro exponente del buen quehacer de los integrantes de la banda Pott. El propio Iturralde ha subrayado que fue precisamente la tradición anglosajona (novela policíaca, cine, ficción de aventuras...) la que sedujo a los componentes del grupo, una tradición a la que llegaron gracias, entre otros, a la biblioteca del maestro Borges.

Poco a poco, la tipología de cuentos se ha ido enriqueciendo y en la actualidad, al igual de lo que ocurre en novela, el panorama es ciertamente ecléctico. Al hilo de las peculiaridades que conforman el panorama posmoderno actual, las tendencias que prevalecen en la cuentística vasca de las últimas décadas pasarían por un realismo, sea de corte fantástico (Hasier Etxeberria, Unai Elorriaga, Imanol Zurutuza...), sea próximo al realismo sucio norteamericano al estilo de Carver o Wolff (Pako Aristi, Xabier Mendiguren, Edorta Jiménez, Xabier Montoia, Arantxa Iturbe, Pello Lizarralde...), relatos de tono culturalista que buscan una reflexión metanarrativa (Juan Garzia Garmendia, Anjel Lertxundi, Iban Zaldua...), narraciones donde la fantasía se tiñe a veces de situaciones absurdas (Karlos Linazasoro, Harkaitz Cano...), Microrrelatos (Iban Zaldua, Joseba Sarrionandia) y, sobre todo, han desaparecido las narraciones de corte experimental de los setenta y se ha recuperado el gusto por contar historias. Esta realidad fragmentada que se vislumbra en los cuentos más recientes, hace suya la influencia del cine, la música o los medios de comunicación y explora nuevos modos de narrar, nuevos ritmos y registros lingüísticos. Aunque no cabe duda de que la novela sigue siendo el género de más prestigio y rentabilidad, el cuento en euskara goza de una presencia editorial y aceptación realmente considerables en nuestro sistema literario. Dejando a un lado antologías de cuentos recientes que responden más a impulsos comerciales que a motivaciones literarias (antologías de cuentos ecológicos, eróticos, etílicos), la acogida que el cuento tiene entre nosotros se debe, en nuestra opinión, a que el género ha sabido explorar con acierto nuevas fórmulas, como, por ejemplo, volúmenes de cuentos interrelacionados (short story cycle) que proponen una lectura que cuestiona los límites entre géneros, híbridos a caballo entre la crónica y la ficción (véase Harkaitz Cano, El puente desafinado, Erein, 2003), o incluso híbridos sugerentes que proponen un viaje poético como el libro: Septentrio (Alberdania, 2001) de Aurelia Arkotxa. Mientras la novela vasca contemporánea mira sobre todo hacia dentro y hacia nuestro pasado histórico más reciente con la intención de deconstruir un discurso histórico que nos resulta ajeno (Guárdame bajo tierra —2000_, de Ramón Saizarbitoria, y El hijo del acordeonista -2003-, de Bernardo Atxaga, son un buen ejemplo de ello), el cuento contemporáneo vasco ha acertado al reflejar la realidad actual vasca, esa realidad conflictiva y fragmentada tan llamativamente representada en cuentos como «Bibliografía», de Iban Zaldua (cf. Olaziregi, M.J. (ant) (2005)), o los que componen el libro Bizia lo (trad.: Letargo, Alberdania, 2005), de Jokin Muñoz. 


\section{Autores y obras.}

Quisiéramos completar este breve repaso al cuento contemporáneo vasco con una pequeña introducción a los autores y cuentos más relevantes. Joseba Sarrionandia (1958) será el primero en el que recalaremos. Es la suya una trayectoria literaria que, junto a los géneros tradicionales (poesía, narrativa, ensayo), gusta de experimentar y proponer textos híbridos representativos de una concepción innovadora de la literatura. Ni ez naiz hemengoa ('Yo no soy de aquí', Hiru, 1985), Marginalia (1988), Ez gara geure baitakoak ('No somos de nosotros mismos', 1989) y Han izanik hona naiz ('De allí mismo vengo', 1992) son algunas de sus obras que presentan esa tendencia a la hibridación. Otros textos nos recuerdan que Sarrionandia es un reconocido poeta que merece un lugar destacado en el actual panorama literario vasco. La lectura de sus libros de poemas -Izuen gordelekuetan barrena ('En los refugios del miedo', 1984), Marinel zaharrak ('Viejos marineros', 1987), Gartzelako poemak ('Poemas de la cárcel', 1992) y Hnuy illa nyba majh yaboo (1995) - nos revela que Sarrionandia es un viajero incansable de las geografías literarias, un marino deslumbrado por un océano de ideas poéticas. Narrazioak ('Narraciones', 1983), Atabala eta euria ('El tambor y la lluvia', 1986) e Ifar Aldeko orduak ('Las horas del norte', 1991) son sus libros de cuentos más conocidos.

La suya es una prosa poética llena de metáforas e imágenes sugerentes, una prosa que incorpora elementos fantásticos y referencias a leyendas y cuentos tradicionales. El lector encontrará en ella sirenas y viejos marinos que delatan las afinidades del autor con autores como Samuel Taylor Coleridge o Herman Melville, personajes como Ginebra o Galahad que rinden homenaje a narraciones del ciclo artúrico, escenarios lúgubres que recuerdan a los relatos de Poe... o cuentos metanarrativos originales. Precisamente, es un viejo marino el que protagoniza uno de los cuentos más conocidos del autor, El viejo marino (incluido en Narrazioak, 1983), y aunque no se percibe ningún albatros de mal agüero rondando a los personajes (comparar con Coleridge), el lector temerá el fatal desenlace de la historia. Microrrelatos incluidos en libros tales como Han izanik hona naiz ('De allí mismo vengo', 1992) y Ez gara geure baitakoak ('No somos de nosotros mismos', 1989) sirven para mostrar la clara evolución que ha tenido la prosa del autor hacia poéticas y voces más posmodernas que gustan de la ironía y del pastiche. Son relatos brevísimos en los que se puede percibir la tendencia a la hibridación de muchos de los textos de Sarrionandia, relatos de una intensidad y agudeza impactante. Un buen ejemplo lo tendríamos en el breve cuento: «Pelea de carneros» (incl. en Ez gara geure baitakoak), que sirvió de inspiración para el cortometraje que se incluyó en La pelota vasca, de Julio Medem.

Tal y como hemos comentado, Obabakoak (1988) de Bernardo Atxaga (1951) fue un hito en la literatura vasca contemporánea. Anjel Lertxundi afirmó que las cosas no volverían a ser iguales entre nosotros tras el premiado libro, y seguramente tenía razón pues con Obabakoak Atxaga demostró que palabras como «periferia» o «literatura minoritaria» no suponían fronteras infranqueables para un escritor vasco o, dicho de otro modo, que se puede ser universal sin dejar de ser genuinamente vasco. Traducida a 26 lenguas es, sin duda, el libro que convirtió a Atxaga el autor vasco más conocido fuera de nuestras fronteras, el más premiado. Ha sido merecedora, entre otros, del "Premio de la Crítica" (1988), "Premio Nacional de Narrativa" (1989), I. "Premio Euskadi" (1989), finalista del European 
Literary Price (1990), "Premio Milepages" de Paris (1991) y el "Premio Tres Coronas" de los Pirineos Atlánticos (1995). Tanto la crítica extranjera como la nacional se hizo eco, en su día, de la calidad literaria de la obra. Entre las felicitaciones que recibió, citaríamos la de E. Suárez Galbán ( cf. The New York Times Book Review, 20-6-93) quien calificó el libro de "paella deliciosa y barroca".

El paisaje afectivo de Obaba se describe como un infinito virtual donde la memoria del narrador va tejiendo un entramado sugerente de historias, historias que combinan la reflexión metanarrativa con estrategias de literatura fantástica. Para ello, el narrador de Obabakoak partía a un viaje intertextual que comenzaba con Las mil y una noches y terminaba con referencias a maestros de los siglos XIX y XX. Este homenaje literario se traduce en citas de cuentos (como el conocido El criado del rico mercader), en resúmenes (como los de los cuentos de Chejov, Waugh y Maupassant en Acerca de los cuentos), paráfrasis con transformaciones temáticoformales (como Wei Lie Deshang), plagios (como en del cuento Torture par espérance de Villiers de l'Isle Adam en Una grieta en la nieve helada), parodias, imitaciones y un largo etcétera. Por si estas referencias fueran pocas, títulos como Margarete y Heinrich, gemelos (cf. G. Trakl) o E. Werfell (cf. F. Werfel), nos hablan del sustrato expresionista de algunos cuentos del libro. Un viaje intertextual, en definitiva, que permitía al autor reflexionar en torno a las relaciones entre la literatura y la vida, o la lucha entre naturaleza y civilización. Tras Obabakoak, Atxaga ha publicado cuentos en diversas antologías colectivas, tales como, Cuentos apátridas (Ediciones B, 1999), Relatos urbanos (Alfaguara, 1994), Una infancia de escritor (Edición de Mercedes Monmany. Xordica, 1997). También ha publicado libros en los que ha incluido su narrativa breve más reciente, tales como, Un traductor a Paris $i$ altres relats (catalán) (La Magrana, 1999), o Tres declaraciones (Fundación BBK, 1997). Alejado de la literatura fantástica, el autor se vale del humor e ironía para narrar unas historias en las que no se renuncia al Atxaga más experimental y vanguardista.

Inazio Mujika Iraola (1963) irrumpió en el panorama literario vasco con un libro de cuentos, Azukrea belazeetan ('Azúcar en los prados', 1987), de tono marcadamente lírico. Próximo al realismo mágico y a autores como Juan Rulfo, la riqueza de imágenes y el poder evocador de su prosa convencieron a lectores y crítica. De hecho, el realismo mágico inundó muchas de las propuestas narrativas vascas de la década de los 80, tales como las novelas Babilonia (1989, publicada en castellano por la editorial Acento, en 1999) de Joan Mari Irigoien, Dos hermanos (1985; publicada en castellano por Ollero y Ramos en 1995) de Bernardo Atxaga, Hamaseigarrenean aidanez ('Ocurrió a la decimosexta', 1983) de Anjel Lertxundi, o cuentos como el premiado «Haizeak iparlaino beltzak dakartzanean» ('Cuando el viento trae nubarrones negros', 1989) de Imanol Zurutuza. Obaba, Belandia... o el Auzunea, de Mujika Iraola, fueron algunas de las geografías imaginarias de las que los autores de sirvieron para plasmar una fantasía que se nutría de la tradición oral vasca, y donde la trasgresión de normas morales se pagaba, como en los cuentos de Rulfo, Faulkner o Atxaga, con el castigo o la metamorfosis. Por eso es tan cruel ese mundo, pues aquellos que son amenazados con la muerte y el castigo siempre son los débiles, como la pobre Regina, protagonista del cuento del mismo nombre. Para acrecentar la inocencia de los más débiles, la mayoría de los cuentos que integran el volumen de Mujika Iraola tienen narradores autodiegéticos de corta edad. Su habla queda impregnada, constantemente, con expresiones del habla infantil. Y es que hablamos de una fantasía que, como bien dijo Rosemary Jackson, sirve para dar 
vOZ al Otro, es decir, al marginado y silenciado por la sociedad. La presencia amenazante de la nieve o del cerezo en flor en los prados presagia en Azukrea belazeetan los terribles hechos que se avecinan. En cuanto a la intertextualidad, son reseñables, además de las claras conexiones con los universos narrativos de Rulfo y Faulkner, las referencias explíctias a C. Pavese o a Kavafis. La trayectoria narrativa de Mujika Iraola siguió nutriéndose de leyendas tradicionales y de una erudición borgesiana en libros posteriores, tales como Hautsaren kronika ('Crónica del polvo', 1994) donde los devaneos de la memoria histórica sirven para ahondar en un pasado que la mayoría de las veces resulta inquietante. La Guerra Civil española o la Segunda Guerra Mundial se han erigido en escenario de otros libros de Mujika Iraola, tales como, Matriuska (1999), o de su novela Gerezi denbora (1998) (publicada en castellano con bajo el título de Tiempo de cerezas por la editorial Alberdania en 2006). Una buena muestra de este tipo de narrativa que tiene como telón de fondo alguno de los conflictos bélicos mencionados lo constituye el cuento "Como los ahogados a la superficie" (incluido en el volumen Pintxos. Nuevos cuentos vascos).

Es de otra índole el pasado que se rememora en Gasteizko bondartzak ('Las playas de Gasteiz', 1997) de Xabier Montoia (1955). En él, la Guerra Civil y la posguerra sirven de punto de arranque para una serie de historias que llegan hasta la última década del pasado siglo. Al igual que en sus novelas, el autor no pretende dar un testimonio histórico documentado, sino mostrar la historia de gente anónima, es decir, las vivencias de unos seres atrapados en una situación realmente dura. Podríamos afirmar que es la ciudad de Vitoria-Gasteiz la verdadera protagonista de Gasteizko hondartzak, una ciudad que se describe como provinciana y donde la represión política y religiosa condiciona, ahoga, la vida de sus habitantes. El excelente «Como el carbón» es el primero de los veintidós cuentos que integran el libro, y narra la relación homosexual del protagonista con uno de los pilotos alemanes que bombardeará Gernika. El juego entre realidad y ficción, los nexos que entre personajes e historias se van estableciendo de un cuento a otro, son algunos de los aciertos que convierten Gasteizko bondartzak en una obra realmente atractiva. Emakume biboteduna ('La mujer bigotuda', 1992) y Baina bihotzak dio ('Pero el corazón dice', 2002) completan la trayectoria cuentística del autor. En el primero, Montoia nos ofreció un conjunto de historias de (des)amor, narradas en tono realista y que no ocultaban una mirada crítica y provocadora. El cuadro de Marcel Duchamp que conformaba la portada del libro (LHOOQ, de 1919, conocido como Mona Lisa con bigote) servía a la perfección para presentar este libro de relatos protagonizados por personajes cuyos comportamientos afectivos se alejaban de cualquier tópico. Otro era el motivo literario que servía de nexo para los cuentos incluidos en el libro Baina bibotzak dio ('Pero el corazón dice', 2002). En él, la nostalgia por la patria servía de excusa narrativa para crear historias en las que el sentimiento de pérdida y alejamiento inundaba las vivencias de los personajes desterrados por diversos motivos. La trayectoria literaria de Montoia también incluye tres poemarios (Anfetamiña, 1983; Likantropo, 1985; Narraztien mintzoa [El habla de los reptiles]; 1988), un libro de crónicas, y cinco novelas, entre las que destacaremos: Blackout (2004). Como dice I. Aldekoa (2004: 226): "Su narrativa procede del mismo universo underground que su poesía. Como nos dice el propio narrador a través del cuento "Ikatza bezain beltz" (Tan negro como el carbón), durante la juventud había descubierto ya las "figuras de rechazo" más estimulantes en la vida y en la literatura: la música, el alcohol, el cine, los coches y el sexo." 
Es el enfoque realista el que también prevalece en los cuentos de Arantxa Iturbe, Harkaitz Cano e Iban Zaldua, aunque los dos últimos no renuncien al género fantástico. Las relaciones de pareja constituyen el núcleo central de las narraciones que Arantxa Iturbe (1964) ha publicado en sus dos libros: Ezer baino lehen ('Antes de nada', 1992) y Lehenago zen berandu (1995; Ya ni siquiera es tarde, Alberdania, 2005). Prevalecen los protagonistas femeninos, mujeres que viven en núcleos urbanos marcados por el estrés y el ritmo frenético diario. Sus narraciones tienen una espontaneidad y frescura que inunda no sólo el registro y los modos de expresión de sus personajes, sino toda la organización de la trama. Y es que la prosa de Iturbe huye del adorno gratuito y del artificio innecesario para, con breves pinceladas y constantes cambios de ritmo narrativo, relatar con ironía las frustraciones, soledades y malentendidos de esos urbanitas tan necesitados de cariño. Si tuviéramos que describir la evolución entre sus dos libros de cuentos, subrayaríamos su mayor tendencia al suspense en los cuentos incluidos en el segundo volumen, así como el aumento de las dosis de ironía.

Son otros los ritmos que inundan la narrativa de Harkaitz Cano (1975). Novelas negras escritas a ritmo de jazz (véase Jazz y Alaska en la misma frase, Seix Barral, 2004); poemarios donde Basquiat, Boris Vian, Maiakovski o Carver se convierten en visitantes ilustres (cf. Interpretación de los temblores, Atenea, 2004); libros de crónicas que demuestran que el escritor vasco es un alumno aventajado de Capote (El puente desafinado, Erein, 2003); citas de películas clásicas de Hollywood..., ese es el universo literario de Cano. Sus cuentos son minimalistas y hablan de ciudades desoladas, de teléfonos que amenazan con irrumpir en medio de la noche, o de crónicas de desamor con silencios ensordecedores. Son los ingredientes que, aderezados con técnicas de novela negra, conforman el universo de su libro Telefono kaiolatua (hay traducción: Enseres de ortopedia inútil, Hiria, 2002). «El colchón», uno de los cuentos más interesantes de Telefono kaiolatua, es una buena muestra del estilo del autor. Como en los cuentos de Chejov o Carver, la mirada del narrador recala en detalles y objetos aparentemente insignificantes, como ese colchón lleno de manchas y sobres de sopa que se erige en la triste radiografía de los náufragos que habitan esa roulotte itinerante. Destacaríamos su prosa poética, una prosa llena de metáforas sugerentes que sirve para dibujar la vida de los antihéroes que puebla el universo narrativo de Cano. Su último libro de cuentos, Neguko zirkua (2005, Susa) ha sido considerado como el mejor de su trayectoria. En él vuelve a aparecer su gusto por el juego literario y esa mirada del narrador que recala en objetos aparentemente insignificantes pero que cobran una intensidad y significado realmente sorprendentes.

Creemos que son pocos los autores vascos que han sabido acertar como lo ha hecho Iban Zaldua (1966) en el género del microrrelato. Humor, agudeza y una ironía a veces corrosiva presiden sus cuentos, pero, sobre todo, Zaldua gusta de los juegos metaliterarios al estilo de Borges, o de la fantasía incrustada en lo cotidiano al estilo de Cortázar. Además de ellos, el cómic, la cultura pop o la ciencia ficción conforman las afinidades literarias del autor. «Duvrescu, o La fortuna es ciega» (cf. Pintxos. Nuevos cuentos vascos) es, por ejemplo, una excelente muestra de cuento metaficcional en el que Zaldua ha sabido desplegar con maestría sus dotes de narrador. Además, uno de los mayores aciertos de la narrativa de Zaldua radica en la originalidad que manifiesta para romper con tópicos e ideas preconcebidas en torno a la literatura, la vida... e, incluso, la realidad vasca, esa realidad difícil y multiforme que tan acertadamente aparece reflejada en sus cuentos. El mundo 
narrativo de Zaldua huye de lo obvio. De ahí la importancia que da a los paratextos de sus libros de cuentos, tales como Gezurrak, gezurrak, gezurrak (2000; trad.: Mentiras, mentiras, mentiras, Lengua de Trapo), Traizioak ('Traiciones', 2001), Itzalak ('Sombras', 2004) o Etorkizuna ('Futuro", 2005), Premio Euskadi de Literatura-2005. Son los suyos relatos muy intensos en los que no sobra ni una palabra, relatos que no dejan indiferente al lector y que más de una vez consiguen dibujar en sus labios una sonrisa. Seguramente será por ello que, a la hora de definir lo que es un cuento, Zaldua no ha dudado en parafrasear a Cheever y recordarnos que el cuento tiene el poder de aliviarnos ante lo inevitable, la muerte. El premiado Etorkizuna (2005, trad. : Porvenir, Lengua de Trapo), es, de momento, el último cuento de libros de Zaldua. En él, el autor ha introducido algunas novedades con respecto a los libros anteriores (como, por ejemplo, la repetición de personajes de un cuento a otro) pero no ha cambiado la ironía y fuerza con que se acerca a esa realidad contemporánea tan difícilmente aprehensible.

Es el sentimiento de angustia existencial el que inunda muchos de los cuentos de Karlos Linazasoro (1962). Para ello, hace suyos los registros y estrategias de la literatura del absurdo, sobre todo de Kafka y de Beckett, y despliega una fantasía que subvierte las leyes de la lógica y tiene toques surrealistas. Delirio, asfixia, crueldad... son sensaciones y vivencias que padecen muchos de sus personajes, sensaciones que les condenan muchas veces a la locura. Entre sus libros de cuentos, destacaremos: Eldarnioak [Delirios] (Erein, 1991), Zer gerta ere [Pase lo que pase] (Alberdania, 1994), Ez balego beste mundurik [Si no hubiera otro mundo] (Alberdania, 2000) y Ipuin errotikoak (Alberdania, 2001). Tras invocar a maestros como Borges, Cortázar, Felisberto Hernández, Rulfo, Saki, Wilcock, Piñera, Chejov, Hrabal, Mrozek, Bernhard... el autor en la nota biográfica incluida en la antología An Anthology of Basque Short Stories (Center for Basque Studies-University of Nevada, Reno, 2004), afirmaba que le gustan los cuentos que incorporan la fantasía, los que no renuncian a un toque lúdico, los que incorporan la crueldad de la vida cotidiana, los que se le enfrentan al lector...cuentos sorprendentes, fuertes, poderosos, sugerentes, cuentos llenos de sorpresas. Así mismo, afirmaba que el humor y la ironía son consustanciales al cuento, que ésas son las únicas armas que nos ayudan a enfrentarnos a la soledad y al absurdo de la vida cotidiana, pues nos ofrecen distancia y protección. Para Linazasoro, el cuento permite transgredir leyes de todo tipo pues es un género que tiene sus propias reglas y que permite, en parte, ese margen de libertad que al escritor le es negado en otros géneros. Una selección de sus cuentos acaba de ver la luz traducida al castellano: Depósito ilegal (Alberdania, 2005). Se trata de un conjunto de diálogos teatrales, narraciones ultracortas casi aforísticas y cuentos de extensión convencional. El humor vuelve a teñir las situaciones más trágicas, el humor y esa atmósfera inquietante que sin duda sorprenderá al lector. La originalidad de Linazasoro en el panorama literario vasco y su buen hacer literario le han hecho merecedor de un lugar destacado entre las voces narrativas vascas contemporáneas.

Se puede decir que, en los trabajos de metaficción, es la relación entre la literatura y la realidad la que se cuestiona. Para Linda Hutcheon, toda metaficción tiene un objetivo didáctico y pretende explicar al lector cuál es el origen del hecho mismo de escribir. Como consecuencia de este modo de proceder, el lector se encuentra ante algo inacabado, algo para lo que su colaboración activa es imprescindible. De algún modo, el lector se vuelve cocreador de esa obra que tiene ante los ojos, o como dijo Roland Barthes, la muerte del autor ha supuesto el renacer del lector. Ese 
es el espacio en el que se mueven autores como Juan Garzia Garmendia o Anjel Lertxundi, quienes gustan de los artefactos literarios de Calvino o de las enseñanzas del maestro Borges. En este sentido, aunque la obra de Anjel Lertxundi (1948) pudiera ser calificada como ecléctica por la constante renovación de las poéticas que subyace tras ella, el autor siempre ha manifestado su inclinación hacia relatos donde el continuo cuestionamiento del acto de escritura nos invita a reflexionar sobre la lectura. Su trayectoria literaria se inicia con la publicación del libro de cuentos: Hunik arrats artean [Hasta la noche] (1970), considerada, como hemos dicho anteriormente, como el primer libro de cuentos modernos en euskara. En él era evidente el influjo del realismo mágico (uno de los cuentos se sitúa en Macondo, y en otro, al igual de lo que ocurre en cuentos conocidos de Rulfo, un narrador muerto se convierte en el guía de los eventos), así como del teatro del absurdo. Los 16 cuentos que integran el volumen, son diversos en cuanto a los temas y estilos, pero ya en ellos, así como en el siguiente libro de cuentos que publicó Lertxundi, Aise eman zenidan eskua [Me diste la mano con facilidad] (1980), se percibe, con claridad, la tendencia del autor hacia narraciones con trasfondo metaficticio. Dicha tendencia también es evidente en libros de relatos posteriores, tales como Urtero da aurten ('Todos los años son este año', 1984) o la novela Los días de la cera (Alfaguara, 2001). En el cuento «Berlín no queda tan lejos» (cf. Pintxos. Nuevos cuentos vascos), el cuadro de La Virgen y el Niño de Jean Fouquet es el que sirve de excusa narrativa para iniciar un viaje literario en el que prevalece la reflexión sobre las conexiones del arte con la vida. ¿Debe el arte ocultar, borrar, las referencias reales en las que se sustenta? He ahí una de las cuestiones que el narrador no duda en plantearnos en este original cuento.

Shakespeare, Melville, Beckett o Borges, son algunos de los autores que Juan Garzia Garmendia (1955) ha traducido, y el libro de cuentos Itzalen itzal (1993. Trad.: Sombra de sombras, Alberdania, 2006) su aportación literaria más lograda. Once cuentos y un epílogo lo conforman, pero, ante todo, se trata de una obra que presenta un ensamblaje de cuentos realmente acertado. El crítico Iñaki Aldekoa (2004:224) ha descrito con acierto las aportaciones del libro de Garzia Garmendia:

Si el autor de El nombre de la rosa se refiere a Borges como Il grande deconstrutore, no será otro el papel que juegue el argentino en Itzalen itzal, de Juan Garzia, cuyo libro, además, debe mucho a la mirada fascinada que renueva el enamoramiento artístico y vital del paisaje cultural italiano. Como ya hizo Manuel Mújica Láinez en su generosa novela Bomarzo, los pueblos, parques e iglesias de Italia atesoran para el autor de Itzalen itzal potenciales de belleza que esperan al artista capaz de despertarlas de su cautividad medieval o renacentista y transmutarlas en historias imperecederas. Borges escribió desde la conciencia de que todo lo grande, hermoso y bueno se había dicho ya alguna vez. (...) El sólido ensamblaje de Itzalen itzal rinde tributo a la belleza y a la memoria de Pisa, San Gimignano, Firenze, Siena, Orvieto, Roma, Perugia, Gubbio, Venezia, Verona y Milano. A Jorge Luis Borges, Italo Calvino o Antonio Tabucchi conviene citarlos por afinidades electivas. El libro contiene algunos cuentos excelentes."

Otras son las poéticas a las que la narrativa de Lourdes Oñederra o de Ixiar Rozas rinden pleitesía. La irrupción, en los últimos años, de nuevas escritoras al mercado editorial vasco protagonizado, hasta ahora, por hombres es, sin duda, uno de los acontecimientos literarios más importantes de nuestra historia más reciente. 
A los ya reconocidos nombres de Arantxa Urretabizkaia, Mariasun Landa, Itxaro Borda, Laura Mintegi o Arantxa Iturbe, se les han sumado narradoras como Lourdes Oñederra, Ana Urkiza o Ixiar Rozas.

Las narraciones de Oñederra y Rozas juegan con las miradas y los silencios que rodean a sus personajes. Y esas miradas significan deseo en los textos narrativos de Lourdes Oñederra (1958): la novela Y la serpiente dijo a la mujer (Bassarai, 2000) y el cuento: «El capricho de la señora Anderson» (incluido en Pintxos. Nuevos cuentos vascos). Como vemos, es la referencia al texto occidental más impactante, a la Biblia, la que condiciona el paratexto de la novela Y la serpiente dijo a la mujer. Sabemos que la serpiente tentó a Eva y le prometió ser poseedora de toda la sabiduría si comía la manzana. Las consecuencias de su actuación son por todos conocidas: la culpa y el castigo. Y en el caso de las mujeres, la condena a vivir sometidas a los hombres. Esta referencia intertextual nos sitúa ante el núcleo temático de la novela ya que, Y la serpiente dijo a la mujer, habla del abismo que hay entre hombres y mujeres, de las incomunicaciones y soledades a las que estamos condenados, o de la sinrazón de las consignas o historias con las que tratamos de dar sentido a nuestras vidas. Condenada a refugiarse en un lenguaje y unos términos que continuamente le traicionan (amor, amistad, ilusión, fidelidad...), Teresa no tiene otra opción que continuar intentándolo. "Contar, decir, hablar", verbos que nos recuerdan la imposibilidad de seguir narrando y la necesidad de tener que hacerlo. Al igual que los personajes de S. Beckett, Teresa sabe que es ese lenguaje el que le sigue conectando a la vida, ese lenguaje que, aunque extremadamente sospechoso (cf. $L$ 'Ére du soupçon), es el único que tiene. De ahí el estilo preciso, comedido, durasiano que utiliza autora en esta novela, un estilo alejado de todo barroquismo y que trata de plasmar las vivencias más intensas con un lenguaje contenido. En cuanto al cuento: «El capricho de la señora Anderson», diremos que la cita de Doris Lessing y su Love, again inician el relato del deseo inconfesado de una señora de edad que no duda en permitirse un pequeño capricho al inicio de cada primavera. El universo narrativo de Oñederra juega con miradas, con interrupciones y repeticiones que marcan el ritmo narrativo, descripciones que derrochan sensualidad..., pero, ante todo, con silencios que buscan la complicidad del lector.

La mirada de otra de las autoras del panorama narrativo vasco actual, Ixiar Rozas (1972), se detiene en elementos y personajes silenciados, en gestos y movimientos que para la mayoría pasarían desapercibidos. Su trayectoria literaria incluye las novelas: Edo zu edo ni [O tú o yo] (2000) y Negutegia [El invernadero] (2006), el poemario Patio bat bi itsasoen artean [Un paio entre dos mares] (2001) y el libro de cuentos Luego les separa la noche (Erein, 2003), traducción de Sartu, korrontea dabil (Erein, 2001). En la narración «Luego les separa la noche», incluido en el libro de mismo título Luego les separa la noche (2003), el lector podrá percibir la mirada solidaria que con la frialdad de una cámara cinematográfica acierta a revelarnos la intensidad y los temores de Abdou, el joven de Mali que viaja a Paris en busca de su padre. Rozas admite su admiración por autores como John Berger, con quien afirma haber aprendido a mirar, a recalar en esos seres marginales que habitan las grandes urbes. Son sus miradas ignoradas, sus discursos silenciados los que hablan en la narrativa de Rozas.

Quisiéramos completar este breve repaso a los nombres más destacados del actual panorama del cuento vasco presentando a Pello Lizarralde (1956), un 
escritor cuyo universo literario brilla por su originalidad y fuerza entre los autores vascos contemporáneos. Podríamos decir que su narrativa es minimalista y que tiene gran poder de sugerencia. El autor acierta a crear unos ambientes realmente emocionantes. Como lo hiciera en su novela Larrepetit ('Langosta', 2002), Lizarralde gusta de presentarnos en el libro de relatos Un ange passe -isialdietan- [Pasa un ángel en los silencios] (1998) personajes que huyen, que están en constante tránsito. Y pocas cosas ocurren realmente en las historias, pocas cosas a excepción de esa mirada omnipresente, de ese foco narrativo que con detallismo casi obsesivo se detiene en los movimientos y gestos en apariencia más insignificantes. El libro de cuentos Sargori (Bochorno, 1994) es un excelente ejemplo del poder poético de la prosa de Lizarralde y de su capacidad para crear una atmósfera agobiante. Un autor, sin duda, a tener en cuenta y cuya trayectoria se ha visto recientemente reconocida con premios como el Euskadi de Literatura (2003) o el Premio de la Crítica (2003) otorgados a la ya mencionada novela Larrepetit.

\section{Bibliografia}

- Aldekoa, I. (2004) Historia de la Literatura Vasca, Donostia, Erein.

— Olaziregi, M.J. (2000) "Un siglo de novela en euskara", in Urquizu, P. (dir), op cit. (ant.) (2005) Pintxos. Nuevos cuentos vascos, Madrid, Lengua de Trapo.

— Urquizu, P., (dir) (2000) Historia de la Literatura Vasca, Madrid, UNED. 